\title{
Thirlwall's Law and uneven development under Global Value Chains: a multi-country input-output approach
}

\author{
Andrew B. Trigg ${ }^{*}$ (D)
}

*Correspondence:

Andrew.Trigg@open.ac.uk Department of Economics, The Open University, Walton Hall, Milton Keynes MK7 6AA, UK

\begin{abstract}
A notable macroeconomic explanation of uneven development, with particular relevance to developing countries, has been the problem of balance of payments constraints, as captured by Thirlwall's Law: where relative growth rates are explained by differences between income elasticities for exports and imports. Araujo and Lima have formulated a one-country multisectoral disaggregation of this hypothesis using a vertically integrated input-output framework, which is extended here in two main ways. First, international trade in intermediate inputs - the basis for Global Value Chains -is introduced; second, the model is extended to multiple countries. The main outcome of the paper is the development of a new multisectoral method for modelling balance of payments constraints: a Multi-Country Sectoral Thirlwall Law (MCSTL) under which key sector relationships are nested in intercountry trading relationships that encompass both intermediate and final goods. The identification of this input-output structure is developed in analytical stages, moving from a one-country vertically integrated system, to two, three and finally multi-country systems. In addition to its theoretical contribution to understanding the industrial structure of trade, an implication of this multi-country/multi-sector approach is that it can also be tested in future empirical work using the recently available World Input-Output Database of national tables.
\end{abstract}

Keywords: Uneven development, Thirlwall's Law, Global Value Chains, Input-output analysis, Vertical integration, Trade in value added

\section{Introduction}

A notable explanation for uneven development between countries has been the problem of balance of payments constraints, as advanced by Thirlwall (1979). For developing countries in particular, this can undermine growth when low-income elasticities for exports combine with high-income elasticities for imports, as captured by Thirlwall's Law, for which the vast majority of studies have provided empirical support (see Thirlwall 2013, Table 5.2). The suggested policy prescription under this balance of payments-constrained growth model is for structural change to promote exports in favour of imports.

This structural change approach has recently been developed with the specification of income elasticities for industrial sectors under the Multisectoral Thirlwall Law

(c) The Author(s) 2020 This article is licensed under a Creative Commons Attribution 4.0 International License, which permits use, sharing adaptation, distribution and reproduction in any medium or format, as long as you give appropriate credit to the original author(s) and the source, provide a link to the Creative Commons licence, and indicate if changes were made. The images or other third party material in this article are included in the article's Creative Commons licence, unless indicated otherwise in a credit line to the material. If material is not included in the article's Creative Commons licence and your intended use is not permitted by statutory regulation or exceeds the permitted use, you will need to obtain permission directly from the copyright holder. To view a copy of this licence, visit http://creativeco mmons.org/licenses/by/4.0/. 
(MSTL), first developed by Araujo and Lima (2007), with its starting point the vertically integrated closed input-output model devised by Pasinetti (1993). Pasinetti shows how under vertical integration different stages of production can be succinctly represented in a model of final consumption: a 'genuinely' macroeconomic approach since relationships hold regardless of the degree of disaggregation (ibid, p. 20). This somewhat abstract theoretical insight has promulgated an emerging empirical literature on Thirlwall's Law in which import and export elasticities have been estimated using econometric functions at the sectoral level (e.g.: Romero and McCombie 2016; Blecker and Ibarra 2013; Romero et al. 2011; Govea and Lima 2010). Valuable insights have been provided into the structure of sectoral elasticities, of particular note being evidence to suggest that some countries should specialise in the production of exports from key high-tech industrial sectors. As argued by Thirlwall (2013, p. 98): 'From a policy point of view, this multisectoral specification of the model allows for the identification of key, strategic, growthpromoting tradable-goods sectors of the economy'.

One problem that has emerged in this literature, however, is the role of Global Value Chains (GVCs) in the specification of sectoral income elasticities. Blecker and Ibarra (2013), for example, show in a study of Mexico that income elasticities are biased if the role of intermediate inputs is not taken into account. Since in a global production network intermediate inputs can be traded multiple times between countries, gross trade flows can fail to locate the original source of value added and overestimate its scale. UNCTAD $(2013, x)$ estimate that such double counting accounts for $28 \%$ of global trade. The problem of double counting has been systematically addressed by a recent literature on the use of input-output analysis-a key technique for analysing national accounts under GVCs - to account for Trade in Value Added (see Los et al. 2015; Koopman et al. 2014; Johnson and Noguera 2012; Stehrer 2012; Daudin et al. 2001; Hummels et al. 2001). By decomposing the input-output accounts, multiple global flows of value added can be traced back to their country of origin. This importance of input-output analysis to modelling GVCs suggests a re-consideration of how Thirlwall's Law can be modelled using the original input-output approach devised by Araujo and Lima (2007).

Drawing on the largely empirical input-output literature developing the notion of Trade in Value Added, the theoretical contribution of this paper is to generalise the Multisectoral Thirlwall Law in order to take into account the structure of Global Value Chains. A new Multi-Country Sectoral Thirlwall Law (MCSTL) is proposed, by extending the one-country Araujo-Lima model to a multi-country input-output framework in which trade in intermediate inputs is fully taken into account. This is a type of multiregional input-output model, originally pioneered by Isard (1951) and Moses (1955), in which each region is a country. Using this input-output approach, an alternative is provided to econometric applications of Thirlwall's Law that have introduced multi-country extensions (see Bagnai et al. 2015; Nell 2003).

There is, in addition, a problem that Pasinetti's closed input-output model generates unit income elasticities, which are not suitable for capturing uneven development. To address this issue an open input-output system is established that incorporates autonomous final consumer expenditures.

In order to delineate the structural characteristics and complex patterns of trade associated with Global Value Chains, the analysis here builds up in incremental steps, 
from the basic one-country aggregate macroeconomic model to two, three and multicountry models. In Sect. 2, Thirlwall's Law is explained in its basic macroeconomic form, followed in Sect. 3 by a consideration of its multisectoral foundations in the Araujo-Lima adaptation of Pasinetti's closed input-output model. In Sect. 4 a twocountry extension of Araujo-Lima is developed, incorporating intermediate inputs and autonomous expenditures. This model is used in Sect. 5 to derive the Multisectoral Thirlwall Law, providing new insights into its structure. Building on these foundations, Sect. 6 turns to the specification of a three-country system, followed in Sect. 7 by a derivation of a new Multi-Country Sectoral Thirlwall Law. Some concluding remarks are provided in Sect. 8.

\section{Thirlwall's Law}

Thirlwall's Law can be introduced for the case of a home economy in which aggregate income $(Y)$ is generated in the production of goods required for consumption $(C)$ and exports $(X)$ :

$$
Y=C+X .
$$

It can also be assumed that all of this income is spent on consumption and imports $(M)$ :

$$
Y=C+M .
$$

It follows from (1) and (2) that there must be balanced trade $(X=M)$. By then letting imports depend both on income, according to the marginal propensity to consume $(m)$, and on autonomous imports $(\bar{M})$, such that

$$
M=m Y+\bar{M},
$$

it also follows that

$$
Y=\frac{1}{m}(X-\bar{M})
$$

(see Thirlwall 2013, p. 82). Demand for exports is the key driver for income according to $1 / m$, the Harrod trade multiplier.

This demand-side approach can be further elaborated using income elasticities. By differentiating (4) with respect to $X$ and (3) with respect to $Y$ :

$$
\frac{\mathrm{d} Y}{\mathrm{~d} X}=\frac{1}{m}=\frac{1}{\frac{\mathrm{d} M}{\mathrm{~d} Y}} .
$$

Since $X=M$, the right-hand side of (5) can be multiplied by $M / Y$ and the left hand side by $X / Y$ so that

$$
\mathrm{d} Y \frac{X}{Y}=\frac{\mathrm{d} X}{\frac{\mathrm{d} M}{\mathrm{~d} Y}} \frac{M}{Y}
$$

or 


$$
\frac{\mathrm{d} Y}{Y}=\frac{\mathrm{d} X}{X} /\left(\frac{\mathrm{d} M}{M} / \frac{\mathrm{d} Y}{Y}\right)
$$

(Thirlwall 2013, p. 121). If $Y_{\mathrm{f}}$ is the income of the foreign country then it also follows that

$$
\frac{\mathrm{d} Y_{\mathrm{f}}}{Y_{\mathrm{f}}} / \frac{\mathrm{d} Y_{\mathrm{f}}}{Y_{\mathrm{f}}}=\left(\frac{\mathrm{d} X}{X} / \frac{\mathrm{d} Y_{\mathrm{f}}}{Y_{\mathrm{f}}}\right) /\left(\frac{\mathrm{d} M}{M} / \frac{\mathrm{d} Y}{Y}\right)
$$

or

$$
\frac{g_{\mathrm{h}}}{g_{\mathrm{f}}}=\frac{\varepsilon}{\pi} .
$$

This is Thirlwall's hypothesis, which has come to be known as Thirlwall's Law, under which, with a balance of trade constraint, the relative growth rates of the home country $\left(g_{\mathrm{h}}\right)$ and the foreign country $\left(g_{\mathrm{f}}\right)$ are governed by the ratio of the income elasticities for exports $(\varepsilon)$ and imports $(\pi)$ (Thirlwall 2013, p. 85).

\section{The Araujo-Lima model}

In an important contribution to understanding how trade and structural change are related, Araujo and Lima (2007) explore the multisectoral foundations of Thirlwall's Law by extending the model of pure labour developed by Pasinetti (1993). This builds on the earlier work of Araujo and Teixeira (2004), with for simplicity exchange rates not considered for this abstract starting point.

In this Pasinetti model, a key abstraction is that labour is the sole factor of production and provides the only source of demand for its output. Although intermediate inputs can be incorporated into this framework (see Sect. 4), they are not explicitly modelled in the first instance in order to focus on the structural relationship between output and demand. This stripped down closed input-output model is shown by Pasinetti to allow a clear focus on the relationship between structural change and demand, before introducing further complexities at a more concrete level of analysis.

Core to the Pasinetti model are per capital consumption coefficients $\left(c_{i}\right)$ defined for each industry $i$ for the home country, which has a total employed population of $N$. Modification of the model to incorporate trade requires the specification of per capita consumption coefficients for exports of each commodity $\left(c_{i}^{\mathrm{e}}\right)$, which depend on employment in the foreign country $\left(N_{\mathrm{f}}\right)$. The key innovation is use of an employment ratio, $\xi=N_{\mathrm{f}} / N$, which allows home employment to be transformed into employment in the foreign country. Hence, the physical output $\left(Q_{i}\right)$ of each commodity is directed in part to exports by combining these coefficients such that $\xi c_{i}^{\mathrm{e}} N=c_{i}^{\mathrm{e}} N_{\mathrm{f}}$, as shown in the quantity equation

$$
Q_{i}=\left(c_{i}+\xi c_{i}^{\mathrm{e}}\right) N
$$

With $l_{i}$ representing labour coefficients, for $S$ single-commodity producing industries the level of employment in the home country is specified as 


$$
N=\sum_{i=1}^{S} l_{i} Q_{i} .
$$

These two equations show the interdependence between production and consumption. In (10), output of each commodity depends on the macroeconomic consumption expenditure of workers, whose employment depends on sectoral output, as captured in (11). Collecting these elements into $S \times 1$ column vectors of outputs (Q), domestic consumption coefficients $(\mathbf{c})$ and export-related consumption coefficients $\left(\mathbf{c}^{\mathrm{e}}\right)$, together with a $1 \times S$ row vector of labour coefficients $(\mathbf{l})$, the quantity system takes the form:

$$
\left[\begin{array}{cc}
\mathbf{I} & -\left(\mathbf{c}+\xi \mathbf{c}^{\mathrm{e}}\right. \\
-\mathbf{l} & 1
\end{array}\right]\left[\begin{array}{l}
\mathbf{Q} \\
N
\end{array}\right]=\left[\begin{array}{l}
\mathbf{0} \\
0
\end{array}\right] .
$$

Dual to this quantity system, the Araujo-Lima price system can be established with a row vector of money prices $(\mathbf{p})$ and a money wage rate $(w)$. With $\mathbf{c}^{\mathrm{m}}$ defined as the column vector of consumption coefficients for imports, the price system can be shown in matrix form as

$$
\left[\begin{array}{ll}
\mathbf{p} & w
\end{array}\right]\left[\begin{array}{cc}
\mathbf{I} & -\left(\mathbf{c}+\mathbf{c}^{\mathrm{m}}\right. \\
-\mathbf{l} & 1
\end{array}\right]=\left[\begin{array}{ll}
\mathbf{0} & 0
\end{array}\right]
$$

Expressions for aggregate income can be derived for each of these systems. From (12) we have

$$
\mathbf{Q}=\mathbf{c} N+\xi \mathbf{c}^{\mathrm{e}} N \text {. }
$$

Pre-multiplying this expression by the vector of money prices:

$$
\mathbf{p Q}=\mathbf{p} \mathbf{c} N+\mathbf{p c}^{\mathbf{e}} \xi N
$$

or

$$
Y=C+X \text {, }
$$

where aggregate income is $Y=\mathbf{p Q}$. From (13), the expression

$$
w=\mathbf{p c}+\mathbf{p} \mathbf{c}^{\mathrm{m}}
$$

can be translated, by post-multiplying by $N$, into

$$
w N=\mathbf{p} \mathbf{c} N+\mathbf{p c}^{\mathrm{m}} N
$$

or

$$
Y=C+M
$$

where $Y=w N$ in the pure labour system. From (15) and (17), the balance of trade $(X=M)$ is established under solution of this extended Pasinetti system.

The Araujo-Lima system is an inventive introduction of trade into a Pasinetti-based multisectoral framework, but with two main limitations. First, the model focuses mainly on the production activity of the home country, with limited treatment of the production system operating in the foreign country. It is ostensibly a one-country model. This 
is somewhat restrictive given the increasingly global structure of production networks between industries across multiple countries.

A second problem is that as a closed input-output model it generates unit income elasticities. To show this finding, the derivation of Thirlwall's Law, in (1) to (9), can first be established with all of its aggregate components formulated under a multisectoral structure. The key macroeconomic aggregate income equations, (1) and (2), have already been derived in (15) and (17) from multisectoral foundations, which ensures that $X=M$. In addition, consider the money value of total imports. Under the assumption in this closed input-output model of zero autonomous imports $(\bar{M}=0)$, then from (17) we know that

$$
M=\mathbf{p c}^{\mathrm{m}} N .
$$

Since $\mathbf{p}=w \mathbf{l}$, from (13), it follows that

$$
M=\mathbf{l} \mathbf{c}^{\mathrm{m}} w N
$$

and

$$
M=\mathbf{l c}^{m} Y .
$$

This provides a multisectoral structure to (3), with $m=\mathbf{l} \mathbf{c}^{\mathrm{m}}$. Having derived (1) to (3) from multisectoral foundation (under the assumption that $\bar{M}=0$ ), then the derivation of Thirlwall's Law in (5) to (9) is established from these multisectoral foundations.

Income elasticities for the Araujo-Lima model can now be specified by first differentiating (20) with respect to income:

$$
\frac{\mathrm{d} M}{\mathrm{~d} Y}=\mathbf{l} \mathbf{c}^{\mathrm{m}} .
$$

Hence, under (20) and (21), the income elasticity for imports is

$$
\pi=\frac{\mathrm{d} M}{\mathrm{~d} Y} \frac{Y}{M}=\frac{\mathbf{l \mathbf { c } ^ { \mathrm { m } } Y}}{\mathbf{l c}^{\mathrm{m}} Y}=1 .
$$

The income elasticity of imports is unitary. With no autonomous components in this closed input-output system, Engel curves go through the origin, generating unit income elasticities. The income elasticity for exports is also unitary since

$$
X=\mathbf{l c}^{\mathrm{e}} Y_{\mathrm{f}}
$$

and

$$
\frac{\mathrm{d} X}{\mathrm{~d} Y_{\mathrm{f}}}=\mathbf{l} \mathbf{c}^{\mathrm{e}},
$$

which yields

$$
\varepsilon=\frac{\mathrm{d} X}{\mathrm{~d} Y_{\mathrm{f}}} \frac{Y_{\mathrm{f}}}{X}=\frac{\mathbf{l} \mathbf{c}^{\mathrm{e}} Y_{\mathrm{f}}}{\mathbf{l} \mathbf{c}^{\mathrm{e}} Y_{\mathrm{f}}}=1
$$


Under balanced trade in the Araujo-Lima model, from (9) Thirlwall's Law generates equal growth rates for the home and foreign countries:

$$
\frac{g_{\mathrm{h}}}{g_{\mathrm{f}}}=\frac{\varepsilon}{\pi}=1 \text {. }
$$

There is no possibility for uneven growth between the two countries under this closed input-output system. An autonomous component is required in order to specify Engel curves with non-unitary income elasticities. This autonomous component has been introduced in studies inspired by Araujo and Lima (2007) to estimate elasticities using econometric functions at the sectoral level (e.g.: Romero and McCombie 2016), but the objective here is to introduce this autonomous component as an extension of their original input-output formulation.

\section{A two-country extension}

In order to address these issues, the one-country Araujo-Lima model can be extended into an explicitly two-country framework in which countries $A$ and $B$ each have their own production systems. Each country produces the same $S$ commodities in different physical quantities, collected in $S \times 1$ column vectors of gross outputs, $\mathbf{X}^{A}$ and $\mathbf{X}^{B}$. These outputs are produced with volumes of labour employed in each country of $N^{A}$ and $N^{B}$. Column vectors of per capita consumption coefficients are intra-country, reflecting consumption of domestic commodities that depends on domestic employment $\left(\mathbf{c}^{A A}\right.$ and $\left.\mathbf{c}^{B B}\right)$ and intercountry, consumed by labour in the other country $\left(\mathbf{c}^{A B}\right.$ and $\left.\mathbf{c}^{B A}\right)$.

Autonomous expenditure on imports can be introduced in order to transform the Araujo-Lima system from a closed to an open input-output system. The column vector $\overline{\mathbf{Q}}^{A B}$ represents autonomous imports of final consumption goods by country $B$ from country $A$; the column vector $\overline{\mathbf{Q}}^{B A}$ represents autonomous imports from $B$ into $A$. These flows are exogenous to the system, independent of economic activity in the two countries.

An additional extension of the Araujo-Lima system, to make it suitable for the study of Global Value Chains, is in the treatment of technology. With labour coefficients collected in row vectors $\mathbf{l}^{A}$ and $\mathbf{l}^{B}$, interindustry technical coefficient matrices, $\mathbf{A}^{A A}$ and $\mathbf{A}^{B B}$, can be defined to capture intermediate input requirements that are produced in each country. Inter-country trade, on the other hand, includes flows of intermediate goods between countries, an increasingly important phenomenon in global production networks. To model this, $\mathbf{A}^{A B}$ is a matrix capturing intermediate inputs imported from country $A$ by country $B$; and $\mathbf{A}^{B A}$ is a matrix of intermediate inputs imported from country $B$ by country $A$. This use of foreign inputs represents the most general type of Global Value Chain relationship, referred to by Baldwin and Lopez-Gonzalez (Baldwin and Lopez-Gonzalez 2015, 1686) as 'importing to produce'.

We are now able to set up an open two-country input-output model:

$$
\left[\begin{array}{cccc}
\mathbf{I}-\mathbf{A}^{A A} & -\mathbf{A}^{A B} & -\mathbf{c}^{A A} & -\mathbf{c}^{A B} \\
-\mathbf{A}^{B A} & \mathbf{I}-\mathbf{A}^{B B} & -\mathbf{c}^{B A} & -\mathbf{c}^{B B} \\
-\mathbf{l}^{A} & \mathbf{0} & 1 & 0 \\
\mathbf{0} & -\mathbf{l}^{B} & 0 & 1
\end{array}\right]\left[\begin{array}{c}
\mathbf{X}^{A} \\
\mathbf{X}^{B} \\
N^{A} \\
N^{B}
\end{array}\right]=\left[\begin{array}{c}
\overline{\mathbf{Q}}^{A B} \\
\mathbf{Q}^{B A} \\
0 \\
0
\end{array}\right]
$$


Following the approach developed in Pasinetti's (1981) one-country system, (27) can now be re-configured in vertically integrated form. Column vectors of final outputs, $\mathbf{Q}^{A}$ and $\mathbf{Q}^{B}$, are defined net of intermediate inputs for each country:

$$
\left[\begin{array}{cc}
\mathbf{I}-\mathbf{A}^{A A} & -\mathbf{A}^{A B} \\
-\mathbf{A}^{B A} & \mathbf{I}-\mathbf{A}^{B B}
\end{array}\right]\left[\begin{array}{l}
\mathbf{X}^{A} \\
\mathbf{X}^{B}
\end{array}\right]=\left[\begin{array}{l}
\mathbf{Q}^{A} \\
\mathbf{Q}^{B}
\end{array}\right] .
$$

We can also define a matrix of vertically integrated labour coefficients, which capture the direct and indirect labour required across the two countries:

$$
\left[\begin{array}{ll}
\mathbf{n}^{A A} & \mathbf{n}^{A B} \\
\mathbf{n}^{B A} & \mathbf{n}^{B B}
\end{array}\right]=\left[\begin{array}{ll}
\mathbf{l}^{A} & \mathbf{0} \\
\mathbf{0} & \mathbf{1}^{B}
\end{array}\right]\left[\begin{array}{ll}
\mathbf{I}-\mathbf{A}^{A A} & -\mathbf{A}^{A B} \\
-\mathbf{A}^{B A} & \mathbf{I}-\mathbf{A}^{B B}
\end{array}\right]^{-1} .
$$

The row vector $\mathbf{n}^{A B}$, for example, captures the (direct and indirect) labour embodied in intermediate goods produced in country $A$, per unit of final consumption in country $B$. Using (28) and (29) the quantity system for the two-country input-output model can be shown in vertically integrated form as

$$
\left[\begin{array}{cccc}
\mathbf{I} & \mathbf{0} & -\mathbf{c}^{A A} & -\mathbf{c}^{A B} \\
\mathbf{0} & \mathbf{I} & -\mathbf{c}^{B A} & -\mathbf{c}^{B B} \\
-\mathbf{n}^{A A} & -\mathbf{n}^{A B} & 1 & 0 \\
-\mathbf{n}^{B A} & -\mathbf{n}^{B B} & 0 & 1
\end{array}\right]\left[\begin{array}{l}
\mathbf{Q}^{A} \\
\mathbf{Q}^{B} \\
N^{A} \\
N^{B}
\end{array}\right]=\left[\begin{array}{l}
\overline{\mathbf{Q}}^{A B} \\
\overline{\mathbf{Q}}^{B A} \\
0 \\
0
\end{array}\right]
$$

which may be written as

$$
\left(\mathbf{I}-\mathbf{A}^{+}\right) \mathbf{Q}=\mathbf{F} .
$$

And, providing matrix $\left(\mathbf{I}-\mathbf{A}^{+}\right)$is non-singular, the system can be solved using a Type II Leontief inverse, $\left(\mathbf{I}-\mathbf{A}^{+}\right)^{-1}$, closed in part with respect to household consumption, such that

$$
\mathbf{Q}=\left(\mathbf{I}-\mathbf{A}^{+}\right)^{-1} \mathbf{F} .
$$

The quantities $\left(\mathbf{Q}^{A}, \mathbf{Q}^{B}, N^{A}, N^{B}\right)$ are determined, via the Leontief inverse, by the autonomous consumption flows contained in $\mathbf{F}$.

Dual to this quantity system a price system can be defined. With given quantities of labour $\left(N^{A}\right.$ and $\left.N^{B}\right)$ determined by autonomous imports $\left(\overline{\mathbf{Q}}^{A B}\right.$ and $\left.\overline{\mathbf{Q}}^{B A}\right)$ set up in the quantity system, we can define autonomous consumption coefficients:

$$
\begin{aligned}
\overline{\mathbf{c}}^{A B} & =\frac{\overline{\mathbf{Q}}^{A B}}{N^{B}} \\
\overline{\mathbf{c}}^{B A} & =\frac{\overline{\mathbf{Q}}^{B A}}{N^{A}} .
\end{aligned}
$$

In order to establish an equilibrium solution to this open input-output system, the consumption coefficients in (33) can be interpreted as given parameters in a price system that is dual to the quantity system: 


$$
\left[\begin{array}{llll}
\mathbf{p}^{A} & \mathbf{p}^{B} & w^{A} & w^{B}
\end{array}\right]\left[\begin{array}{cccc}
\mathbf{I} & \mathbf{0} & -\mathbf{c}^{A A} & -\left(\mathbf{c}^{A B}+\overline{\mathbf{c}}^{A B}\right) \\
\mathbf{0} & \mathbf{I} & -\left(\mathbf{c}^{B A}+\overline{\mathbf{c}}^{B A}\right) & -\mathbf{c}^{B B} \\
-\mathbf{n}^{A A} & -\mathbf{n}^{A B} & 1 & 0 \\
-\mathbf{n}^{B A} & -\mathbf{n}^{B B} & 0 & 1
\end{array}\right]=\left[\begin{array}{llll}
\mathbf{0} & 0 & 0 & 0
\end{array}\right]
$$

Row vectors of money prices ( $\mathbf{p}^{A}$ and $\mathbf{p}^{B}$ ) represent value added, which in this system are wage costs captured by scalar money wage rates $\left(w^{A}\right.$ and $\left.w^{A}\right)$. For simplicity, in the analysis that follows a uniform wage rate $w=w^{A}=w^{B}$ is assumed across all countries, a restriction that could in principle be a relaxed at a later stage of analysis.

Equations (1) to (3) in the derivation of Thirlwall's Law can be established for this two-country case. From (30) and (34) it follows that for country $A$ :

$$
\begin{gathered}
\mathbf{Q}^{A}=\mathbf{c}^{A A} N^{A}+\mathbf{c}^{A B} N^{B}+\overline{\mathbf{Q}}^{A B} \\
w=\mathbf{p}^{A} \mathbf{c}^{A A}+\mathbf{p}^{B}\left(\mathbf{c}^{B A}+\overline{\mathbf{c}}^{B A}\right) .
\end{gathered}
$$

Pre-multiplying (35) by the vector of prices and post-multiplying (36) by the total employment for country $A$ :

$$
\begin{gathered}
\mathbf{p}^{A} \mathbf{Q}^{A}=\mathbf{p}^{A} \mathbf{c}^{A A} N^{A}+\mathbf{p}^{A}\left(\mathbf{c}^{A B} N^{B}+\overline{\mathbf{Q}}^{A B}\right) \\
w N^{A}=\mathbf{p}^{A} \mathbf{c}^{A A} N^{A}+\mathbf{p}^{B}\left(\mathbf{c}^{B A}+\overline{\mathbf{c}}^{B A}\right) N^{A} .
\end{gathered}
$$

These represent multisectoral versions of the income Eqs. (1) and (2) when $A$ is the domestic economy and the constituent elements are:

$$
\begin{aligned}
& Y=\mathbf{p}^{A} \mathbf{Q}^{A}=w N^{A}, \\
& C=\mathbf{p}^{A} \mathbf{c}^{A A} N^{A}, \\
& X=\mathbf{p}^{A}\left(\mathbf{c}^{A B} N^{B}+\overline{\mathbf{Q}}^{A B}\right), \\
& M=\mathbf{p}^{B}\left(\mathbf{c}^{B A}+\overline{\mathbf{c}}^{B A}\right) N^{A} .
\end{aligned}
$$

Thus since $Y=C+X$ and $Y=C+M$, it follows that under a solution to this two-country model balanced trade $(X=M)$ is guaranteed. Using (39), the multisectoral version of (3) is also established from (42) with $\bar{M}=\mathbf{p}^{B} \overline{\mathrm{c}}^{B A} N^{A}$ and $m=\left(\mathbf{n}^{A B}+\mathbf{n}^{B B}\right) \mathbf{c}^{B A}$. The rest of the derivation of Thirlwall's Law in (4) to (9) thus follows from these multisectoral foundations. By the same reasoning, Thirlwall's Law can also easily be established for country $B$ under solution of this two-country system.

In this input-output framework, a distinction can be made between flows of intermediate and final consumption goods. In Global Value Chains, it is necessary to capture flows of value added required to produce imports and exports: referred to as Trade in Value Added (TiVA) (see Johnson and Noguera 2012; Stehrer 2012). These can be first 
identified for the case of imports to country $A$. From the quantity system (30), we have expressions for employment and output:

$$
\begin{aligned}
& N^{B}=\mathbf{n}^{B A} \mathbf{Q}^{A}+\mathbf{n}^{B B} \mathbf{Q}^{B}, \\
& \mathbf{Q}^{A}=\mathbf{c}^{A A} N^{A}+\mathbf{c}^{A B} N^{B}+\overline{\mathbf{Q}}^{A B}, \\
& \mathbf{Q}^{B}=\mathbf{c}^{B A} N^{A}+\mathbf{c}^{B B} N^{B}+\overline{\mathbf{Q}}^{B A},
\end{aligned}
$$

Substituting (44) and (45) into (43):

$$
N^{B}=\mathbf{n}^{B A} \mathbf{c}^{A A} N^{A}+\mathbf{n}^{B A} \mathbf{c}^{A B} N^{B}+\mathbf{n}^{B A} \overline{\mathbf{Q}}^{A B}+\mathbf{n}^{B B} \mathbf{c}^{B A} N^{A}+\mathbf{n}^{B B} \mathbf{c}^{B B} N^{B}+\mathbf{n}^{B B} \overline{\mathbf{Q}}^{B A}
$$

Re-arranging, and multiplying throughout by the wage rate $(w)$, the income $\left(Y^{B}=w N^{B}\right)$ for country $B$ has the structure

$$
\begin{aligned}
Y^{B}= & w \mathbf{n}^{B B}\left(\overline{\mathbf{Q}}^{B A}+\mathbf{c}^{B A} N^{A}\right)+w \mathbf{n}^{B A} \mathbf{c}^{A A} N^{A} \\
& +w \mathbf{n}^{B A}\left(\overline{\mathbf{Q}}^{A B}+\mathbf{c}^{A B} N^{B}\right)+w \mathbf{n}^{B B} \mathbf{c}^{B B} N^{B} .
\end{aligned}
$$

Elements of this expression can be considered each in turn. The first term $\left(w \mathbf{n}^{B B}\left(\overline{\mathbf{Q}}^{B A}+\mathbf{c}^{B A} N^{A}\right)\right.$ captures, via $w \mathbf{n}^{B B}$, the value added by country $B$ in its production of final goods (autonomous and endogenous) exported to country $A$. The second term, $\left(w \mathbf{n}^{B A} \mathbf{c}^{A A} N^{A}\right)$ captures country $B$ 's value added embodied in intermediate goods, via $\mathbf{n}^{B A}$, that are exported to country $A$ for use in its domestically produced final good consumption. This trade in final and intermediate goods makes up the TiVA of imports by country $A$ from Country $B$ (to be used in the next section to derive the Multisectoral Thirlwall Law):

$$
M^{B A}=w \mathbf{n}^{B B}\left(\overline{\mathbf{Q}}^{B A}+\mathbf{c}^{B A} N^{A}\right)+w \mathbf{n}^{B A} \mathbf{c}^{A A} N^{A} .
$$

It may be noted for completion that the remaining terms to consider in (47) capture value added created and extinguished in country $B$. The third term, $w \mathbf{n}^{B A}\left(\overline{\mathbf{Q}}^{A B}+\mathbf{c}^{A B} N^{B}\right)$, captures value added in country $B$ in the production of intermediate goods that are exported to country $A$ for subsequent use in the production of exports of final goods (autonomous and endogenous) back to country $B$. This is a supply chain sequence, referred to by Baldwin and Lopez-Gonzalez $(2015,1686)$ as 'reimporting. These flows are not included in TiVA, but accounted for as part of country B's domestically produced value added. The final term, $w \mathbf{n}^{B B} \mathbf{c}^{B B} N^{B}$, captures country B's domestically produced value added embodied in domestic consumption

A symmetrical TiVA expression for exports from country $A$ into country $B$ takes the form

$$
X^{A B}=w \mathbf{n}^{A A}\left(\overline{\mathbf{Q}}^{A B}+\mathbf{c}^{A B} N^{B}\right)+w \mathbf{n}^{A B} \mathbf{c}^{B B} N^{B}
$$

Again the first term captures valued added flows in final goods, with the second term representing flows in intermediate goods. As shown above, balanced trade is established in this model such that $M^{B A}=X^{A B}$, measured as Trade in Value Added. In the analysis 
that follows the structure of Thirlwall's Law will be further explored under this in-built constraint.

\section{The Multisectoral Thirlwall Law}

Using this input-output system, it is possible to consider the structure of sectoral income elasticities. To illustrate how this works it can be assumed that each country has two singlecommodity producing industries $(S=2)$. A constituent element of the column vector of consumption coefficients ( $\mathbf{c}^{B A}$ ), for example, is $c_{1}^{B A}$, which represents the consumption of Country B's output of commodity 1 per unit of employment in Country $A$.

Using (48), the starting point is to focus on the money value of each of the two commodities imported by Country $A$ from Country $B$ :

$$
\begin{aligned}
& M_{1}^{B A}=w n_{1}^{B B} \bar{Q}_{1}^{B A}+w n_{1}^{B A} c_{1}^{A A} N^{A}+w n_{1}^{B B} c_{1}^{B A} N^{A} \\
& M_{2}^{B A}=w n_{2}^{B B} \bar{Q}_{2}^{B A}+w n_{2}^{B A} c_{2}^{A A} N^{A}+w n_{2}^{B B} c_{2}^{B A} N^{A} .
\end{aligned}
$$

Now with income constituted by wages $\left(Y^{A}=w N^{A}\right)$, (50) can be re-expressed as

$$
\begin{aligned}
& M_{1}^{B A}=w n_{1}^{B B} \bar{Q}_{1}^{B A}+\left(n_{1}^{B A} c_{1}^{A A}+n_{1}^{B B} c_{1}^{B A}\right) Y^{A} \\
& M_{2}^{B A}=w n_{2}^{B B} \bar{Q}_{2}^{B A}+\left(n_{2}^{B A} c_{2}^{A A}+n_{2}^{B B} c_{2}^{B A}\right) Y^{A}
\end{aligned}
$$

Hence the total money value of imports into country $A$ from $B$ is

$$
M^{B A}=w\left(n_{1}^{B B} \bar{Q}_{1}^{B A}+n_{2}^{B B} \bar{Q}_{2}^{B A}\right)+\left(n_{1}^{B A} c_{1}^{A A}+n_{1}^{B B} c_{1}^{B A}+n_{2}^{B A} c_{2}^{A A}+n_{2}^{B B} c_{2}^{B A}\right) Y^{A}
$$

Derivatives of these import quantities with respect to income can then be specified as

$$
\begin{aligned}
& \frac{\mathrm{d} M_{1}^{B A}}{\mathrm{~d} Y^{A}}=n_{1}^{B A} c_{1}^{A A}+n_{1}^{B B} c_{1}^{B A} \\
& \frac{\mathrm{d} M_{2}^{B A}}{\mathrm{~d} Y^{A}}=n_{2}^{B A} c_{2}^{A A}+n_{2}^{B B} c_{2}^{B A} \\
& \frac{\mathrm{d} M^{B A}}{\mathrm{~d} Y^{A}}=n_{1}^{B A} c_{1}^{A A}+n_{1}^{B B} c_{1}^{B A}+n_{2}^{B A} c_{2}^{A A}+n_{2}^{B B} c_{2}^{B A} .
\end{aligned}
$$

Using these derivatives, the multisectoral structure of income elasticities can be established. Examination of (53) shows that the derivative of total imports with respect to income is decomposed into a summation of the two derivatives for each industry:

$$
\frac{\mathrm{d} M^{B A}}{\mathrm{~d} Y^{A}}=\frac{\mathrm{d} M_{1}^{B A}}{\mathrm{~d} Y^{A}}+\frac{\mathrm{d} M_{2}^{B A}}{\mathrm{~d} Y^{A}} .
$$

These derivatives can be manipulated to give an expression for the income elasticity for imports of

$$
\frac{\mathrm{d} M^{B A}}{\mathrm{~d} Y^{A}} \frac{Y^{A}}{M^{B A}}=\frac{\mathrm{d} M_{1}^{B A}}{\mathrm{~d} Y^{A}} \frac{Y^{A}}{M_{1}^{B A}} \frac{M_{1}^{B A}}{M^{B A}}+\frac{\mathrm{d} M_{2}^{B A}}{\mathrm{~d} Y^{A}} \frac{Y^{A}}{M_{2}^{B A}} \frac{M_{2}^{B A}}{M^{B A}} .
$$

With the income elasticity for imports of each commodity expressed as $\pi_{i}^{B A}$ and by defining weightings, $\omega_{i}^{B A}=M_{i}^{B A} / M^{B A}$, the income elasticity can be written as 


$$
\pi^{B A}=\pi_{1}^{B A} \omega_{1}^{B A}+\pi_{2}^{B A} \omega_{2}^{B A} .
$$

Without showing all of the same steps, symmetrical to the derivation presented from (50) to (56), the income elasticity for imports into $B$ from $A$ takes the form:

$$
\pi^{A B}=\pi_{1}^{A B} \omega_{1}^{A B}+\pi_{2}^{A B} \omega_{2}^{A B} .
$$

It can be noted that the income elasticity of imports into $B$ from $A$ is also the income elasticity for exports from $A$ to $B: \pi^{A B}=\varepsilon^{A B}$. Hence, using (9), as derived earlier in Sect. 4 for the two-country model, together with (56) and (57), relative growth rates are expressed as the ratio of income elasticities:

$$
\frac{g_{A}}{g_{B}}=\frac{\varepsilon^{A B}}{\pi^{B A}}=\frac{\pi_{1}^{A B} \omega_{1}^{A B}+\pi_{2}^{A B} \omega_{2}^{A B}}{\pi_{1}^{B A} \omega_{1}^{B A}+\pi_{2}^{B A} \omega_{2}^{B A}} .
$$

This is the Multisectoral Thirlwall Law as devised by Araujo and Lima (2007), for the illustrative case of two sectors. As mentioned earlier, despite its original evolution from the work of Pasinetti, subsequent research on this multisectoral variant of the Law has moved away from its input-output foundations. Its derivation here provides a succinct interface between the problem of uneven development, as captured by the ratio of growth rates, and input-output technology, as embodied in multisectoral income elasticities for imports and exports.

Lying behind these income elasticities is a complex value chain of interrelationships between sectors across countries. To give some insight into how this structure governs uneven development, using (53) for imports, and the same approach for exports, (58) can be re-expressed as

$$
\frac{g_{A}}{g_{B}}=\frac{\left(n_{1}^{A B} c_{1}^{B B}+n_{1}^{A A} c_{1}^{A B}\right) \frac{Y^{B}}{M_{1}^{A B}} \frac{M_{1}^{A B}}{M^{A B}}+\left(n_{2}^{A B} c_{2}^{B B}+n_{2}^{A A} c_{2}^{A B}\right) \frac{Y^{B}}{M_{2}^{A B}} \frac{M_{2}^{A B}}{M^{A B}}}{\left(n_{1}^{B A} c_{1}^{A A}+n_{1}^{B B} c_{1}^{B A}\right) \frac{Y^{A}}{M_{1}^{B A}} \frac{M_{1}^{B A}}{M^{B A}}+\left(n_{2}^{B A} c_{2}^{A A}+n_{2}^{B B} c_{2}^{B A}\right) \frac{Y^{A}}{M_{2}^{B A}} \frac{M_{2}^{B A}}{M^{B A}}} .
$$

Through cancellation of terms, and since under Thirlwall's Law there is a balance of trade equality $\left(M^{A B}=M^{B A}\right)$ :

$$
\frac{g_{A}}{g_{B}}=\frac{Y^{B}}{Y^{A}} \frac{\left(n_{1}^{A B} c_{1}^{B B}+n_{1}^{A A} c_{1}^{A B}+n_{2}^{A B} c_{2}^{B B}+n_{2}^{A A} c_{2}^{A B}\right)}{\left(n_{1}^{B A} c_{1}^{A A}+n_{1}^{B B} c_{1}^{B A}+n_{2}^{B A} c_{2}^{A A}+n_{2}^{B B} c_{2}^{B A}\right)}
$$

Relative growth rates therefore have two theoretical explanations. The first involves the ratio of income levels in each country. Since $Y^{A}=w N^{A}$ and $Y^{B}=w N^{B}$ it follows that

$$
\frac{Y^{B}}{Y^{A}}=\frac{N^{B}}{N^{A}}=\xi
$$

This is the ratio of employment levels between the two countries $(\xi)$, shown in Sect. 3 to be central to Araujo and Lima's one-country modelling of exports using the Pasinetti closed input-output model (see Eq. 12). This employment ratio is shown here to retain a core role in understanding relative growth rates in a two-country open input-output framework: 


$$
\frac{g_{A}}{g_{B}}=\xi \frac{\left(n_{1}^{A B} c_{1}^{B B}+n_{1}^{A A} c_{1}^{A B}+n_{2}^{A B} c_{2}^{B B}+n_{2}^{A A} c_{2}^{A B}\right)}{\left(n_{1}^{B A} c_{1}^{A A}+n_{1}^{B B} c_{1}^{B A}+n_{2}^{B A} c_{2}^{A A}+n_{2}^{B B} c_{2}^{B A}\right)}
$$

If, for example, country $A$ was underdeveloped (compared to $B$ ), then its growth rate would benefit the higher is the size of the other economy, country $B$. Larger, richer economies have a role to play in fostering the development of poorer economies.

The second theoretical explanation operates at the sectoral level. Consider, for example, the two elements in the numerator of (62) for sector 1, each of which is a linear combination of an employment multiplier and consumption coefficient. In the first element, $n_{1}^{A B} c_{1}^{B B}$, the employment multiplier, $n_{1}^{A B}$, captures the labour embodied in intermediate goods produced in $A$ required to produce consumption goods, represented by the consumption coefficient, $c_{1}^{B B}$, produced and consumed in $B$. These are global supply chain purchases of intermediate inputs by country $B$ from country $A$. The second expression, $n_{1}^{A A} c_{1}^{A B}$, consists of a domestic employment multiplier, $n_{1}^{A A}$, for intermediate inputs produced in country $A$ for use in country A's production of consumption goods, represented by $c_{1}^{A B}$, exported to country B: more traditional trade in final consumption goods. This provides a more in depth insight into the identification of key sectors than under the Multisectoral Thirlwall Law. Whereas the numerator of (58) suggests an examination of the income elasticity for exports, and its proportionate share of trade weighted for sector $1, \pi_{1}^{A B} \omega_{1}^{A B}$, a more in depth disaggregated analysis is provided by distinguishing between supply chain trade of intermediate goods and the more traditional trade in final goods. This distinction can be drawn for each of the sectors in an input-output system.

This has implications for key sector analysis. A sector may have a high income elasticity for exports, and a high weighting, but this may disguise an underlying imbalance; the sector may, for example, have weak trade linkages for final goods alongside strong linkages for intermediate goods, or vice versa. By deriving the Multisectoral Thirlwall Law, under an input-output system, key sectors are no longer chosen just by identifying sectors with high income elasticities that make up a significant proportion of trade. The export potential of sectors can also be explored by distinguishing between intermediate and final good trade linkages.

\section{A three-country extension}

More interesting value chain linkages emerge once a third country is introduced, this being key to discovering the structure of the global multi-country relationships in Sect. 7. In addition to countries $A$ and $B$, a new third country, $C$, can be considered.

Extending Eq. (30), the quantity system for three countries, each with $S$ sectors, has the structure

$$
\left[\begin{array}{cccccc}
\mathbf{I} & \mathbf{0} & \mathbf{0} & -\mathbf{c}^{A A} & -\mathbf{c}^{A B} & -\mathbf{c}^{A C} \\
\mathbf{0} & \mathbf{I} & \mathbf{0} & -\mathbf{c}^{B A} & -\mathbf{c}^{B B} & -\mathbf{c}^{B C} \\
\mathbf{0} & \mathbf{0} & \mathbf{I} & -\mathbf{c}^{C A} & -\mathbf{c}^{C B} & -\mathbf{c}^{C C} \\
-\mathbf{n}^{A A} & -\mathbf{n}^{A B} & -\mathbf{n}^{A C} & 1 & 0 & 0 \\
-\mathbf{n}^{B A} & -\mathbf{n}^{B B} & -\mathbf{n}^{B C} & 0 & 1 & 0 \\
-\mathbf{n}^{C A} & -\mathbf{n}^{C B} & -\mathbf{n}^{C C} & 0 & 0 & 1
\end{array}\right]\left[\begin{array}{c}
\mathbf{Q}^{A} \\
\mathbf{Q}^{B} \\
\mathbf{Q}^{C} \\
N^{A} \\
N^{B} \\
N^{C}
\end{array}\right]=\left[\begin{array}{c}
\overline{\mathbf{Q}}^{A B}+\overline{\mathbf{Q}}^{A C} \\
\overline{\mathbf{Q}}^{B A}+\overline{\mathbf{Q}}^{B C} \\
\overline{\mathbf{Q}}^{C A}+\overline{\mathbf{Q}}^{C B} \\
0 \\
0 \\
0
\end{array}\right]
$$


In order to derive Thirlwall's Law (Eq. 9) for a three-country system, we rely here on the derivation provided in the Appendix for the general $R$ country case; this is the special case under which $R=3$.

For exploration of the structure of Thirlwall's Law, the analysis will focus on imports into country $A$ from countries $B$ and $C$, each in turn. Consider first the expression for employment relating to country $B$

$$
N^{B}=\mathbf{n}^{B A} \mathbf{Q}^{A}+\mathbf{n}^{B B} \mathbf{Q}^{B}+\mathbf{n}^{B C} \mathbf{Q}^{C} .
$$

The expressions relating to output for all three countries are:

$$
\begin{aligned}
& \mathbf{Q}^{A}=\mathbf{c}^{A A} N^{A}+\mathbf{c}^{A B} N^{B}+\mathbf{c}^{A C} N^{C}+\overline{\mathbf{Q}}^{A B}+\overline{\mathbf{Q}}^{A C} . \\
& \mathbf{Q}^{B}=\mathbf{c}^{B A} N^{A}+\mathbf{c}^{B B} N^{B}+\mathbf{c}^{B C} N^{C}+\overline{\mathbf{Q}}^{B A}+\overline{\mathbf{Q}}^{B C} . \\
& \mathbf{Q}^{C}=\mathbf{c}^{C A} N^{A}+\mathbf{c}^{C B} N^{B}+\mathbf{c}^{C C} N^{C}+\overline{\mathbf{Q}}^{C A}+\overline{\mathbf{Q}}^{C B} .
\end{aligned}
$$

Substituting (65), (66) and (67) into (64) yields

$$
\begin{aligned}
N^{B}= & \mathbf{n}^{B A} \mathbf{c}^{A A} N^{A}+\mathbf{n}^{B A} \mathbf{c}^{A B} N^{B}+\mathbf{n}^{B A} \mathbf{c}^{A C} N^{C}+\mathbf{n}^{B A} \overline{\mathbf{Q}}^{A B}+\mathbf{n}^{B A} \overline{\mathbf{Q}}^{A C} \\
& +\mathbf{n}^{B B} \mathbf{c}^{B A} N^{A}+\mathbf{n}^{B B} \mathbf{c}^{B B} N^{B}+\mathbf{n}^{B B} \mathbf{c}^{B C} N^{C}+\mathbf{n}^{B B} \overline{\mathbf{Q}}^{B A}+\mathbf{n}^{B B} \overline{\mathbf{Q}}^{B C} \\
& +\mathbf{n}^{B C} \mathbf{c}^{C A} N^{A}+\mathbf{n}^{B C} \mathbf{c}^{C B} N^{B}+\mathbf{n}^{B C} \mathbf{c}^{C C} N^{C}+\mathbf{n}^{B C} \overline{\mathbf{Q}}^{C A}+\mathbf{n}^{B C} \overline{\mathbf{Q}}^{C B} .
\end{aligned}
$$

Following the same derivation as in Eqs. (43) to (48), from (68) a new expression, that includes linkages with the third country $C$, is derived for imports into country $A$ from country $B$ :

$$
M^{B A}=w\left(\mathbf{n}^{B B} \overline{\mathbf{Q}}^{B A}+\mathbf{n}^{B C} \overline{\mathbf{Q}}^{C A}\right)+w\left(\mathbf{n}^{B A} \mathbf{c}^{A A} N^{A}+\mathbf{n}^{B B} \mathbf{c}^{B A} N^{A}+\mathbf{n}^{B C} \mathbf{c}^{C A} N^{A}\right) .
$$

Compared to the import expression for the two-country model (48), there are two new third-party elements. First, $w \mathbf{n}^{B C} \overline{\mathbf{Q}}^{C A}$ shows the value added that flows from country $B$ to country $C$, embodied in intermediate inputs, to produce final goods that are autonomously demanded from country $C$ by country $A$. Second, $w \mathbf{n}^{B C} \mathbf{C}^{C A} N^{A}$ shows value added, embodied in intermediate inputs, from $B$ to $C$, for final goods endogenously demanded by country $A$. This use of foreign inputs has been referred to in the literature as 'importing to export' (Baldwin and Lopez-Gonzalez 2015, 1686); Hummels et al. (2001) call it 'vertical specialization'. It represents a subset of the more general 'importing to produce' category, focusing specifically on the importing of intermediate goods for use in the production of exports.

A second expression for imports from country $C$ into country $A$ can be derived using the employment equation from (63):

$$
N^{C}=\mathbf{n}^{C A} \mathbf{Q}^{A}+\mathbf{n}^{C B} \mathbf{Q}^{B}+\mathbf{n}^{C C} \mathbf{Q}^{C} .
$$

Substituting (65), (66) and (67) into (70) gives 


$$
\begin{aligned}
N^{C}= & \mathbf{n}^{C A} \mathbf{c}^{A A} N^{A}+\mathbf{n}^{C A} \mathbf{c}^{A B} N^{B}+\mathbf{n}^{C A} \mathbf{c}^{A C} N^{C}+\mathbf{n}^{C A} \overline{\mathbf{Q}}^{A B}+\mathbf{n}^{C A} \overline{\mathbf{Q}}^{A C} \\
& +\mathbf{n}^{C B} \mathbf{c}^{B A} N^{A}+\mathbf{n}^{C B} \mathbf{c}^{B B} N^{B}+\mathbf{n}^{C B} \mathbf{c}^{B C} N^{C}+\mathbf{n}^{C B} \overline{\mathbf{Q}}^{B A}+\mathbf{n}^{C B} \overline{\mathbf{Q}}^{B C} \\
& +\mathbf{n}^{C C} \mathbf{c}^{C A} N^{A}+\mathbf{n}^{C C} \mathbf{c}^{C B} N^{B}+\mathbf{n}^{C C} \mathbf{c}^{C C} N^{C}+\mathbf{n}^{C C} \overline{\mathbf{Q}}^{C A}+\mathbf{n}^{C C} \overline{\mathbf{Q}}^{C B} .
\end{aligned}
$$

Using the same steps as before,

$$
M^{C A}=w\left(\mathbf{n}^{C C} \overline{\mathbf{Q}}^{C A}+\mathbf{n}^{C B} \overline{\mathbf{Q}}^{B A}\right)+w\left(\mathbf{n}^{C A} \mathbf{c}^{A A} N^{A}+\mathbf{n}^{C B} \mathbf{c}^{B A} N^{A}+\mathbf{n}^{C C} \mathbf{c}^{C A} N^{A}\right) .
$$

Hence, total imports of value added into country $A$ are $M^{A}=M^{B A}+M^{C A}$, which from (69) and (72), with $Y^{A}=w N^{A}$, is

$$
\begin{aligned}
M^{A}= & w\left(\mathbf{n}^{B B} \overline{\mathbf{Q}}^{B A}+\mathbf{n}^{B C} \overline{\mathbf{Q}}^{C A}+\mathbf{n}^{C C} \overline{\mathbf{Q}}^{C A}+\mathbf{n}^{C B} \overline{\mathbf{Q}}^{B A}\right) \\
& +\left(\mathbf{n}^{B A} \mathbf{c}^{A A}+\mathbf{n}^{B B} \mathbf{c}^{B A}+\mathbf{n}^{B C} \mathbf{c}^{C A}+\mathbf{n}^{C A} \mathbf{c}^{A A}+\mathbf{n}^{C B} \mathbf{c}^{B A}+\mathbf{n}^{C C} \mathbf{c}^{C A}\right) Y^{A} .
\end{aligned}
$$

Hence the derivative of imports against income is

$$
\frac{\mathrm{d} M^{A}}{\mathrm{~d} Y^{A}}=\mathbf{n}^{B A} \mathbf{c}^{A A}+\mathbf{n}^{B B} \mathbf{c}^{B A}+\mathbf{n}^{B C} \mathbf{c}^{C A}+\mathbf{n}^{C A} \mathbf{c}^{A A}+\mathbf{n}^{C B} \mathbf{c}^{B A}+\mathbf{n}^{C C} \mathbf{c}^{C A} .
$$

Finally, turning to exports, the employment equation from (63) for country $A$ can be considered:

$$
N^{A}=\mathbf{n}^{A A} \mathbf{Q}^{A}+\mathbf{n}^{A B} \mathbf{Q}^{B}+\mathbf{n}^{A C} \mathbf{Q}^{C} .
$$

Again by substituting (65), (66) and (67) into the employment Eq. (75),

$$
\begin{aligned}
N^{A}= & \mathbf{n}^{A A} \mathbf{c}^{A A} N^{A}+\mathbf{n}^{A A} \mathbf{c}^{A B} N^{B}+\mathbf{n}^{A A} \mathbf{c}^{A C} N^{C}+\mathbf{n}^{A A} \overline{\mathbf{Q}}^{A B}+\mathbf{n}^{A A} \overline{\mathbf{Q}}^{A C} \\
& +\mathbf{n}^{A B} \mathbf{c}^{B A} N^{A}+\mathbf{n}^{A B} \mathbf{c}^{B B} N^{B}+\mathbf{n}^{A B} \mathbf{c}^{B C} N^{C}+\mathbf{n}^{A B} \overline{\mathbf{Q}}^{B A}+\mathbf{n}^{A B} \overline{\mathbf{Q}}^{B C} \\
& +\mathbf{n}^{A C} \mathbf{c}^{C A} N^{A}+\mathbf{n}^{A C} \mathbf{c}^{C B} N^{B}+\mathbf{n}^{A C} \mathbf{c}^{C C} N^{C}+\mathbf{n}^{A C} \overline{\mathbf{Q}}^{C A}+\mathbf{n}^{A C} \overline{\mathbf{Q}}^{C B} .
\end{aligned}
$$

Selecting out the export-related terms, total exports of country $A$, to both of the other countries, are

$$
\begin{aligned}
X^{A}= & w\left(\mathbf{n}^{A A} \overline{\mathbf{Q}}^{A B}+\mathbf{n}^{A C} \overline{\mathbf{Q}}^{C B}+\mathbf{n}^{A A} \overline{\mathbf{Q}}^{A C}+\mathbf{n}^{A B} \overline{\mathbf{Q}}^{B C}\right) \\
& +w\left(\mathbf{n}^{A A} \mathbf{c}^{A C} N^{C}+\mathbf{n}^{A B} \mathbf{c}^{B C} N^{C}+\mathbf{n}^{A C} \mathbf{c}^{C C} N^{C}\right) \\
& +\left(\mathbf{n}^{A A} \mathbf{c}^{A B}+\mathbf{n}^{A B} \mathbf{c}^{B B}+\mathbf{n}^{A C} \mathbf{c}^{C B}\right) Y^{B},
\end{aligned}
$$

where $Y^{B}=w N^{B}$. The derivative of country $A$ 's exports with respect to income in country $B$ is hence

$$
\frac{\mathrm{d} X^{A}}{\mathrm{~d} Y^{B}}=\mathbf{n}^{A A} \mathbf{c}^{A B}+\mathbf{n}^{A B} \mathbf{c}^{B B}+\mathbf{n}^{A C} \mathbf{c}^{C B} .
$$

Adapting (62), a three-country structure for Thirlwall's Law can therefore be established, with relative growth rates defined using (74) and (78): 


$$
\frac{g_{A}}{g_{B}}=\xi \frac{\frac{\mathrm{d} X^{A}}{\mathrm{~d} Y^{B}}}{\frac{\mathrm{d} M^{A}}{\mathrm{~d} Y^{A}}}=\xi \frac{\mathbf{n}^{A A} \mathbf{c}^{A B}+\mathbf{n}^{A B} \mathbf{c}^{B B}+\mathbf{n}^{A C} \mathbf{c}^{C B}}{\mathbf{n}^{B A} \mathbf{c}^{A A}+\mathbf{n}^{B B} \mathbf{c}^{B A}+\mathbf{n}^{B C} \mathbf{c}^{C A}+\mathbf{n}^{C A} \mathbf{c}^{A A}+\mathbf{n}^{C B} \mathbf{c}^{B A}+\mathbf{n}^{C C} \mathbf{c}^{C A}}
$$

As in the two-country model, Thirlwall's Law has a multisectoral structure. Each term in (79) is an aggregate of sectoral components. In the $S$ sector case, the first term in the numerator, for example, has the structure:

$$
\mathbf{n}^{A A} \mathbf{c}^{A B}=\left[\begin{array}{llll}
n_{1}^{A A} & n_{2}^{A A} & \cdots & n_{S}^{A A}
\end{array}\right]\left[\begin{array}{c}
c_{1}^{A B} \\
c_{2}^{A B} \\
\vdots \\
c_{S}^{A B}
\end{array}\right]=\sum_{i=1}^{s} n_{i}^{A A} c_{i}^{A B}
$$

As we have seen, the three-country structure also introduces new third-party linkages, incorporated here into Thirlwall's Law. The term, $\mathbf{n}^{A C} \mathbf{c}^{C B}$, in the numerator, captures the labour embodied in exports of intermediate inputs from country $A$ to $C$ that are imported to export', embodied in exports to country $B$. These third-party linkages are also present in the denominator, with $\mathbf{n}^{B C} \mathbf{c}^{C A}$ representing the labour embodied by country $B$ (via intermediate inputs) in exports of final goods from country $C$ to $A$. Finally, $\mathbf{n}^{C B} \mathbf{c}^{B A}$ represents the labour embodied by country $C$ in exports of final goods from $B$ to $A$. All three countries in this model are linked together in an interdependent global production network.

\section{The Multi-Country Sectoral Thirlwall Law}

A final step is to generalise this multisectoral disaggregation of Thirlwall's Law to a multicountry setting. Preliminary to this, the three-country version can be further examined, with Eq. (79) written as

$$
\frac{g_{A}}{g_{B}}=\xi \frac{\mathbf{n}_{A} \mathbf{c}^{B}}{\mathbf{n}_{B} \mathbf{c}^{A}+\mathbf{n}_{C} \mathbf{c}^{A}}
$$

where terms are collected in vectors:

$$
\begin{aligned}
& \mathbf{n}_{A}=\left[\begin{array}{ll}
\mathbf{n}^{A A} \mathbf{n}^{A B} \mathbf{n}^{A C}
\end{array}\right], \\
& \mathbf{n}_{B}=\left[\begin{array}{ll}
\mathbf{n}^{B A} \mathbf{n}^{B B} & \mathbf{n}^{B C}
\end{array}\right], \\
& \mathbf{n}_{C}=\left[\begin{array}{ll}
\mathbf{n}^{C A} \mathbf{n}^{C B} \mathbf{n}^{C C}
\end{array}\right], \\
& \mathbf{c}^{A}=\left[\begin{array}{l}
\mathbf{c}^{A A} \\
\mathbf{c}^{B A} \\
\mathbf{c}^{C A}
\end{array}\right], \quad \mathbf{c}^{B}=\left[\begin{array}{l}
\mathbf{c}^{A B} \\
\mathbf{c}^{B B} \\
\mathbf{c}^{C B}
\end{array}\right]
\end{aligned}
$$

Thirlwall's Law is based here on the ratio of labour embodied in exports from country $A$ to $B$ to the labour embodied in all imports into country $A$, an insight that will now be built upon for the multi-country case.

With numbered superscripts (1 for country 1, 2 for country 2, etc.), the quantity system for $R$ countries takes the form 
$\left[\begin{array}{ccccc} & \mathbf{I} & \mathbf{0} & \cdots & \mathbf{0} \\ & \mathbf{0} & \mathbf{I} & \cdots & \mathbf{0} \\ & \vdots & \vdots & \ddots & \vdots \\ & \mathbf{0} & \mathbf{0} & \cdots & \mathbf{I} \\ -\mathbf{n}^{11} & -\mathbf{n}^{12} & \cdots & -\mathbf{n}^{1 R} \\ -\mathbf{n}^{21} & -\mathbf{n}^{22} & \cdots & -\mathbf{n}^{2 R} \\ \vdots & \vdots & & \ddots & \vdots \\ -\mathbf{n}^{R 1} & -\mathbf{n}^{R 2} & \cdots & -\mathbf{n}^{R R}\end{array}\right.$

$\left.\begin{array}{ccccc}-\mathbf{c}^{11} & -\mathbf{c}^{12} & \cdots & -\mathbf{c}^{1 R} \\ -\mathbf{c}^{21} & -\mathbf{c}^{22} & \cdots & -\mathbf{c}^{2 R} \\ \vdots & \vdots & & \ddots & \vdots \\ -\mathbf{c}^{R 1} & -\mathbf{c}^{R 2} & \cdots & -\mathbf{c}^{R R} \\ & 1 & 0 & \cdots & 0 \\ 0 & 1 & \cdots & 0 \\ \vdots & \vdots & \ddots & \vdots \\ 0 & 0 & \cdots & 1\end{array}\right]\left[\begin{array}{c}\mathbf{Q}^{1} \\ \mathbf{Q}^{2} \\ \vdots \\ \mathbf{Q}^{R} \\ N^{1} \\ N^{2} \\ \vdots \\ N^{R}\end{array}\right]=\left[\begin{array}{c}\overline{\mathbf{Q}}^{1} \\ \overline{\mathbf{Q}}^{2} \\ \vdots \\ \overline{\mathbf{Q}}^{R} \\ 0 \\ 0 \\ \vdots \\ 0\end{array}\right]$

where the multisectoral structure of each component is

$$
\begin{array}{ll}
\mathbf{n}^{i j}=\left[\begin{array}{llll}
n_{1}^{i j} & n_{2}^{i j} & \cdots & n_{S}^{i j}
\end{array}\right], \\
\mathbf{c}^{i j}=\left[\begin{array}{c}
c_{1}^{i j} \\
c_{2}^{i j} \\
\vdots \\
c_{S}^{i j}
\end{array}\right], \quad \mathbf{Q}^{i}=\left[\begin{array}{c}
Q_{1}^{i} \\
Q_{2}^{i} \\
\vdots \\
Q_{S}^{i}
\end{array}\right], \quad \text { and } \quad \overline{\mathbf{Q}}^{i}=\left[\begin{array}{c}
\overline{\mathbf{Q}}_{1}^{i} \\
\overline{\mathbf{Q}}_{2}^{i} \\
\vdots \\
\overline{\mathbf{Q}}_{S}^{i}
\end{array}\right]
\end{array}
$$

Each vector in (82) is a collection of $S$ sectoral terms, with superscripts indicating inter-country relationships. Multiple sectoral and inter-country value chain linkages are captured by each (vertically integrated) vector of labour coefficients $\mathbf{n}^{i j}$, representing the (direct and indirect) labour embodied in intermediate goods exported for each sector from country $i$ to country $j$. The element $n_{2}^{34}$, for example, shows the labour embodied in intermediate goods produced in sector 2 in country 3 that are exported to country 4 . This trade in intermediate goods, as characterised by Global Value Chains, is captured for $R$ countries.

Trade in final goods is captured by the consumption coefficients, $\mathbf{c}^{i j}$, representing the consumption of goods by country $j$ that are produced by each sector in country $i$. For example, the element $c_{2}^{13}$ captures country 3's consumption of good 2 , as produced in sector 2 of country 1 .

The derivation of Thirlwall's Law for this multi-country/multi-sector model is provided in the Appendix. Using this model, and replicating the pattern identified for Thirlwall's Law in (81), for any two countries $i$ and $j$, we have

$$
\frac{g_{i}}{g_{j}}=\xi \frac{\mathbf{n}_{i} \mathbf{c}^{j}}{\left(\sum_{k=1}^{R} \mathbf{n}_{k}-\mathbf{n}_{i}\right) \mathbf{c}^{i}},
$$

where $\xi=N^{j} / N^{i}$ is the employment ratio, and the remaining terms consist of vectors:

$$
\begin{aligned}
& \mathbf{n}_{i}=\left[\begin{array}{llll}
\mathbf{n}^{i 1} & \mathbf{n}^{i 2} & \cdots & \mathbf{n}^{i R}
\end{array}\right], \\
& \mathbf{n}_{k}=\left[\begin{array}{llll}
\mathbf{n}^{k 1} & \mathbf{n}^{k 2} & \cdots & \mathbf{n}^{k R}
\end{array}\right],
\end{aligned}
$$




$$
\begin{aligned}
& \mathbf{c}^{j}=\left[\begin{array}{c}
\mathbf{c}^{1 j} \\
\mathbf{c}^{2 j} \\
\vdots \\
\mathbf{c}^{R j}
\end{array}\right], \quad \text { and } \\
& \mathbf{c}^{i}=\left[\begin{array}{c}
\mathbf{c}^{1 i} \\
\mathbf{c}^{2 i} \\
\vdots \\
\mathbf{c}^{R i}
\end{array}\right] .
\end{aligned}
$$

A new generalised version of Thirlwall's Law is suggested by (83), which may be referred to as the Multi-Country Sectoral Thirlwall Law (MCSTL). Despite the high degree of disaggregation, it has a simple structure. In addition to the employment ratio, the relative growth rates of any two countries $i$ and $j$ depends the ratio of the labour embodied in sectoral exports $\mathbf{n}_{i} \mathbf{c}^{j}$ from $i$ to $j$ to the labour embodied in total sectoral imports $\left(\sum_{k=1}^{R} \mathbf{n}_{k}-\mathbf{n}_{i}\right) \mathbf{c}^{i}$ into country $i$. This is a genuinely macroeconomic relationship that holds regardless of the degree of disaggregation across sectors and countries.

The model incorporates trade in both final and intermediate goods. Consider first the trade in just final goods. For example, when $i=2$ (denoting country 2) and $j=3$ (denoting country 3 ) the term in the numerator, $\mathbf{n}^{i 2} \mathbf{c}^{2 j}$ is equal to $\mathbf{n}^{22} \mathbf{c}^{23}$. This shows the labour carried out in country 2 embodied in exports of final goods from country 2 to 3 . The MCSTL models all of these final good linkages across $S$ sectors and $R$ countries.

Second, consider $\mathbf{n}^{i 2} \mathbf{c}^{2 j}$ when $i=1$ (denoting country 1 ) and $j=4$ (denoting country 4 ) such that it equals $\mathbf{n}^{12} \mathbf{c}^{24}$. This captures the labour embodied in intermediate goods produced in country 1 for use in country 2 for the production of final consumption goods exported to country 4 . In this example, trade in both intermediate and final goods is captured: one of the multiple 'imported to export' relationships that are incorporated in this multiple country model. If this linear combination of employment multiplier $\left(\mathbf{n}^{12}\right)$ and consumption coefficient $\left(\mathbf{c}^{24}\right)$ is strong, a key inter-country relationship is indicated. Further nested within this inter-country relationship are possible key sector relationships; in this example we have $\mathbf{n}^{12} \mathbf{c}^{24}=n_{1}^{12} c_{1}^{24}+n_{2}^{12} c_{2}^{24}+\cdots+n_{S}^{12} c_{S}^{24}$, from which a strong linear combination can be identified for any key sector. This general system allows for the identification of key inter- country relationships, and within these key inter-sector relationships, incorporating trade in intermediate and final goods, for all $S$ sectors across $R$ countries in a global production network.

\section{Concluding remarks}

A new multi-country/multi-sectoral model of Thirlwall's Law is developed here that extends the one-country input-output model of Araujo and Lima (2007) that is based on Pasinetti's system of vertical integration (Pasinetti, 1993). In addition to its generalisation to $R$ countries, this model allows for non-unitary income elasticities by accounting for autonomous expenditure in an open input-output system. Furthermore, it introduces tradeable intermediate inputs in Global Value Chains, building on the recent empirical input-output literature (e.g. Los et al. 2015; Johnson 
and Noguera 2012). Global linkages identified in the latter include the importing of intermediate inputs for export production, accounted for as Trade in Value Added. A demonstration is provided here of how such complex value chain linkages can be succinctly captured using Pasinetti's framework of vertical integration: an alternative perspective and contribution to the input-output literature.

Thirlwall's Law is re-interpreted in two main ways. First, the Multisectoral Thirlwall Law (MSTL) is disaggregated to take into account two types of trade, in intermediate and final goods. Instead of examining income elasticities for exports and imports, a more detailed disaggregation is proposed in which key sector analysis distinguishes between intermediate and final good linkages. Second, this new disaggregated version is generalised to a Multi-Country Sectoral Thirlwall Law (MCSTL). Key inter-country relationships can be identified, of which key sector analysis is a constituent part. Uneven development is shown to depend on a global production network of intermediate inputs and final goods traded between multiple countries.

This multi-country/multi-sector approach to modelling Thirlwall's Law has the additional merit that there is on hand a relatively new dataset available for its possible testing and application: the World Input-Output Database, made up of national tables with interlinking trade flows (see Dietzenbacher et al. 2013). The theoretical model developed here is some way from being concrete enough to be modelled empirically since, for example, there is as yet no category for value added other than wages, and no variation in wage rates, assumptions that will be relaxed in future research.

Acknowledgements

I would like to thank Theo Papaioannou and David Wield for their support and encouragement with this project, and two anonymous referees for extremely helpful comments on the paper. All remaining errors are my responsibility.

Authors' contributions

The paper is single authored. The author read and approved the final manuscript.

Funding

The research is funded solely by the university at which the author is based.

Availability of data and materials

Not applicable.

Competing interests

The author declares no competing interests.

\section{Appendix: Deriving Thirlwall's Law for an $R$ country system}

In order to derive Thirlwall's Law in a multi-country system it is convenient to specify autonomous consumption terms to include intra-country interactions such that in (82):

$$
\begin{gathered}
\overline{\mathbf{Q}}^{1}=\overline{\mathbf{Q}}^{11}+\overline{\mathbf{Q}}^{12}+\cdots+\overline{\mathbf{Q}}^{1 R} \\
\overline{\mathbf{Q}}^{2}=\overline{\mathbf{Q}}^{21}+\overline{\mathbf{Q}}^{22}+\cdots+\overline{\mathbf{Q}}^{2 R} \\
\vdots \\
\overline{\mathbf{Q}}^{R}=\overline{\mathbf{Q}}^{R 1}+\overline{\mathbf{Q}}^{R 2}+\cdots+\overline{\mathbf{Q}}^{R R}
\end{gathered}
$$


The autonomous consumption coefficients (determined in the quantity system) are thus

$$
\overline{\mathbf{c}}^{i j}=\frac{\overline{\mathbf{Q}}^{i j}}{N^{j}}
$$

Using these coefficients, and maintaining the assumption of a uniform wage rate, the dual $R$ country price system takes the form

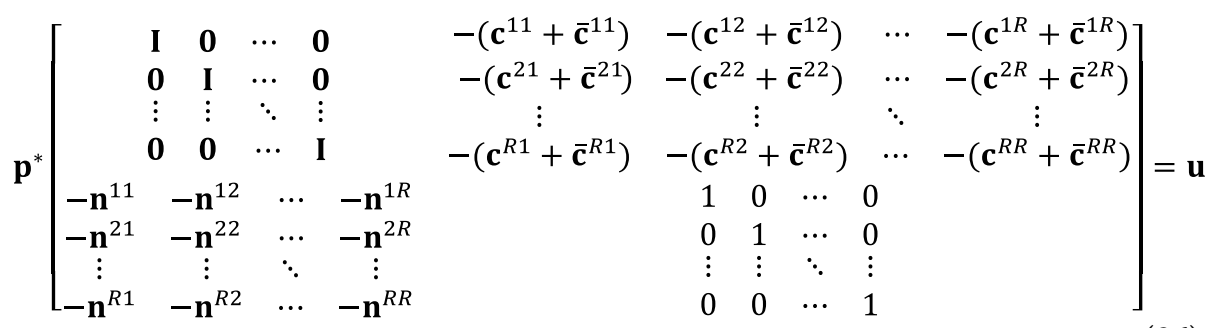

for which $\mathbf{u}$ is a row vector of zeros,

$$
\mathbf{u}=\left[\begin{array}{llllllll}
\mathbf{0} & \mathbf{0} & \cdots & \mathbf{0} & 0 & 0 & \cdots & 0
\end{array}\right]
$$

and $\mathbf{p}^{*}$ is the price vector

$$
\mathbf{p}^{*}=\left[\begin{array}{lllllll}
\mathbf{p}^{1} & \mathbf{p}^{2} & \cdots & \mathbf{p}^{R} w & w & \cdots & w
\end{array}\right]
$$

From (82) and (86), it follows that for any country $i$ :

$$
\begin{aligned}
& \mathbf{Q}^{i}=\mathbf{c}^{i 1} N^{1}+\mathbf{c}^{i 2} N^{2}+\cdots+\mathbf{c}^{i R} N^{R}+\overline{\mathbf{Q}}^{i} \\
& w=\mathbf{p}^{1}\left(\mathbf{c}^{1 i}+\overline{\mathbf{c}}^{1 i}\right)+\mathbf{p}^{2}\left(\mathbf{c}^{2 i}+\overline{\mathbf{c}}^{2 i}\right)+\cdots+\mathbf{p}^{R}\left(\mathbf{c}^{R i}+\overline{\mathbf{c}}^{R i}\right) .
\end{aligned}
$$

Pre-multiplying (89) by the vector of prices, and post-multiplying (90) by total employment:

$$
\begin{aligned}
& \mathbf{p}^{i} \mathbf{Q}^{i}=\mathbf{p}^{i} \mathbf{c}^{i 1} N^{1}+\mathbf{p}^{i} \mathbf{c}^{i 2} N^{2}+\cdots+\mathbf{p}^{i} \mathbf{c}^{i R} N^{R}+\mathbf{p}^{i} \overline{\mathbf{Q}}^{i} \\
& w N^{i}=\mathbf{p}^{1}\left(\mathbf{c}^{1 i}+\overline{\mathbf{c}}^{1 i}\right) N^{i}+\mathbf{p}^{2}\left(\mathbf{c}^{2 i}+\overline{\mathbf{c}}^{2 i}\right) N^{i}+\cdots+\mathbf{p}^{R}\left(\mathbf{c}^{R i}+\overline{\mathbf{c}}^{R i}\right) N^{i}
\end{aligned}
$$

Noting that $Y^{i}=\mathbf{p}^{i} \mathbf{Q}^{i}=w N^{i}$, writing the elements of $\overline{\mathbf{Q}}^{i}$ explicitly using (84), and collecting elements together using summation notation:

$$
\begin{aligned}
Y^{i} & =\sum_{j=1}^{R} \mathbf{p}^{i} \mathbf{c}^{i j} N^{j}+\sum_{j=1}^{R} \mathbf{p}^{i} \overline{\mathbf{Q}}^{i j} \\
Y^{i} & =\sum_{j=1}^{R} \mathbf{p}^{j} \mathbf{c}^{j i} N^{i}+\sum_{j=1}^{R} \mathbf{p}^{j} \overline{\mathbf{c}}^{j i} N^{i} .
\end{aligned}
$$


Using a Kronecker delta (where $\delta_{i j}=1$ if $i=j ; \delta_{i j}=0$ if $i \neq j$ ) we can decompose each of these two expressions for income into two parts:

$$
Y^{i}=\left(\sum_{j=1}^{R} \delta_{i j} \mathbf{p}^{i} \mathbf{c}^{i j} N^{j}+\sum_{j=1}^{R} \delta_{i j} \mathbf{p}^{i} \overline{\mathbf{Q}}^{i j}\right)+\left(\sum_{j=1}^{R}\left(1-\delta_{i j}\right) \mathbf{p}^{i} \mathbf{c}^{i j} N^{j}+\sum_{j=1}^{R}\left(1-\delta_{i j}\right) \mathbf{p}^{i} \overline{\mathbf{Q}}^{i j}\right),
$$

such that

$$
Y^{i}=C^{i}+X^{i}
$$

and

$$
\begin{aligned}
Y^{i}= & \left(\sum_{j=1}^{R} \delta_{i j} \mathbf{p}^{j} \mathbf{c}^{j i} N^{i}+\sum_{j=1}^{R} \delta_{i j} \mathbf{p}^{j} \overline{\mathbf{c}}^{j i} N^{i}\right) \\
& +\left(\sum_{j=1}^{R}\left(1-\delta_{i j}\right) \mathbf{p}^{j} \mathbf{c}^{j i} N^{i}+\sum_{j=1}^{R}\left(1-\delta_{i j}\right) \mathbf{p}^{j} \overline{\mathbf{c}}^{j i} N^{i}\right),
\end{aligned}
$$

such that

$$
Y^{i}=C^{i}+M^{i}
$$

These are the income equations shown in (1) and (2) for the derivation of Thirlwall's Law, shown here in multisectoral form for the general multi-country case. The first parts of each expression are equal (that is when $i=j$ ), giving the domestic consumption $\left(C^{i}\right)$ for country $i$. This ensures, as before, that there is balanced trade for each country $i$, that is $X^{i}=M^{i}$ in this $R$ country input-output system.

Using previous notation employed in (83), it can then be noted from (86) that $\mathbf{p}^{j}=w \mathbf{n}_{j}$ where $\mathbf{n}_{j}=\left(\mathbf{n}^{j 1}+\mathbf{n}^{j 2}+\cdots+\mathbf{n}^{j R}\right)$. Thus, the expression for imports, in the second part of (97), can be written as

$$
M^{i}=\sum_{j=1}^{R}\left(1-\delta_{i j}\right) \mathbf{p}^{j} \overline{\mathbf{Q}}^{j i}+\left(\sum_{j=1}^{R}\left(1-\delta_{i j}\right) \mathbf{n}_{j} \mathbf{c}^{j i}\right) Y^{i}
$$

or

$$
M^{i}=\bar{M}^{i}+m Y^{i} .
$$

From this expression for imports, Eq. (3) of the Thirlwall's Law derivation is also established here in multi-sectoral/multi-country form. The rest of the derivation in (4) to (9) follows from this starting point. 
References

Araujo RA, Lima GT (2007) A structural economic dynamics approach to balance-of-payments-constrained growth. Camb J Econ 31:755-774

Araujo RA, Teixeira JR (2004) A Pasinettian approach to international economic relations: the pure labour case. Rev Political Econ 16(1):117-129

Bagnai A, Rieber A, Tran TA (2015) Sub-Saharan Africa's growth, South-South trade and the generalised balance-of-payments constraint. Camb J Econ 40(3):797-820

Baldwin R, Lopez-Gonzalez J (2015) Supply-chain trade: a portrait of global patterns and several testable hypotheses. World Econ 38(11):1682-1721

Blecker RA, Ibarra CA (2013) Trade liberalization and the balance of payments constraint with intermediate imports: the case of Mexico revisited. Struct Change Econ Dyn 25:33-47

Daudin G, Rifflart C, Schweisguth D (2001) Who produces for whom in the world economy? Can J Econ 44(4):1403-1437

Dietzenbacher E, Los B, Stehrer R, Timmer M, de Vries G (2013) The construction of world input-output tables in the WIOD project. Econ Syst Res 25:71-98

Govea RR, Lima GT (2010) Structural change, balance-of-payments constraint, and economic growth: evidence from the multisectoral Thirlwall's law. J Post Keynes Econ 33:169-204

Hummels D, Ishii J, Yi KM (2001) The nature and growth of vertical specialization in world trade. J Int Econ 54:75-96

Isard W (1951) Interregional and regional input-output analysis: a model of a space-economy. Rev Econ Stat 33:318-328

Johnson RC, Noguera G (2012) Accounting for intermediates: production sharing and trade in value added. J Int Econ 86:224-236

Koopman R, Wang Z, Wei S-J (2014) Tracing value-added and double counting in gross exports. Am Econ Rev 104(2):459-494

Los B, Timmer MP, de Vries GJ (2015) How global are Global Value Chains? A new approach to measure international fragmentation. J Reg Sci 55(1):66-92

Moses $L$ (1955) The stability of interregional trading patterns and input-output analysis. Am Econ Rev 45:803-826

Nell KS (2003) A'generalised'version of the balance-of-payments growth model: an application to neighbouring regions. Int Rev Appl Econ 17(3):249-267

Pasinetti LL (1981) Structural change and economic growth. Cambridge University Press, Cambridge

Pasinetti LL (1993) Structural economic dynamics. Cambridge University Press, Cambridge

Romero JP, McCombie JSL (2016) The multi-sectoral Thirlwall's Law: evidence from 14 developed countries using product-level data. Int Rev Appl Econ 30(3):301-325

Romero JP, Silveira F, Jayme FG Jr (2011) Brazil: structural change and balance-of-payments-constrained growth. CEPAL Rev 105:173-195

Stehrer R (2012) 'Trade in value added and the value added in trade'WIOD Working Paper 8, World Input Output Database. www.wiod.org

Thirlwall AP (1979) The balance of payments constraint as an explanation of international growth rate differences. Banca Nazionale del Lavoro Q Rev 32(128):45-53

Thirlwall AP (2013) Economic growth in an open developing economy. Edward Elgar, Cheltenham

UNCTAD (2013) World investment report. UN: Geneva

\section{Publisher's Note}

Springer Nature remains neutral with regard to jurisdictional claims in published maps and institutional affiliations.

\section{Submit your manuscript to a SpringerOpen ${ }^{\circ}$ journal and benefit from:}

- Convenient online submission

- Rigorous peer review

Open access: articles freely available online

- High visibility within the field

Retaining the copyright to your article

Submit your next manuscript at $\gg$ springeropen.com 